\title{
U.S. Survey Investigating Gaps between Patients and Specialists in the Treatment of Severe Hypoglycemia and Impressions of the Ease-of-Use of Liquid-Stable Glucagon for Subcutaneous Injection
}

\author{
James M. Meyer* and Mary C. Devona
}

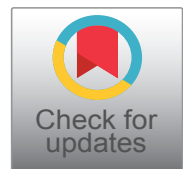

Xeris Pharmaceuticals, USA

*Corresponding author: James Meyer, PharmD, Xeris Pharmaceuticals, Inc. Chicago, 180 N. Lasalle Street, Suite 1600, Chicago, Illinois 60601, USA, Tel: 312-736-1641

\begin{abstract}
Background: Severe hypoglycemia is an emergency condition where very low blood sugar may lead to confusion, seizure, unconsciousness, and if left untreated, death. It has been identified as a cause for recurrent morbidity in people with either Type 1 Diabetes (T1D) or Type 2 Diabetes (T2D); however, the understanding of signs and symptoms of Severe Hypoglycemia (SH), as well as when to use glucagon, tend to vary between patients, caregivers, and adult and pediatric endocrinologists (specialists). The purpose of this study was to identify gaps in knowledge, attitudes, and perceptions between persons with diabetes (PWD) and specialists when it comes to severe hypoglycemia, and to validate whether Gvoke HypoPen ${ }^{\circledR}$ (glucagon injection) and Gvoke ${ }^{\circledR}$ PFS (glucagon injection) are easy-to-use and provide confidence in ability to administer among patients, caregivers, and specialists.
\end{abstract}

Methods: A quantitative analysis was conducted via an online survey among 200 U.S. Healthcare Providers (HCPs) (100 endocrinologists, 100 pediatric endocrinologists) and 400 U.S. self-reported PWD [100 adults with Type 1 Diabetes (T1D), 100 adult caregivers of pediatric patients with Type 1 Diabetes (T1D CG), 100 adults with Type 2 diabetes on basal insulin but not meal-time insulin (T2D $\mathrm{BI}), 100$ adults with Type 2 diabetes on basal and mealtime insulin (T2D MTI)].

Results: Nearly all groups (T1D = 95\%; T1D CG = 94\%; T2D MTI = 94\%; T2D BI = 93\%; Specialists = 95\%) believe that Gvoke Hypopen is easy-to-use. A disconnect exists between specialists and adult patients over the importance of discussing signs and symptoms of severe hypoglycemia.
There are significant gaps between Type 1 PWD, Caregivers of children with T1D, and specialists on when to administer glucagon for treatment of severe hypoglycemia. While there are gaps between Type 2 PWD and specialists on when to administer glucagon for the treatment of severe hypoglycemia, these gaps are narrower - sometimes they are even in alignment.

Conclusions: While gaps exist between patients, caregivers, and specialists on the importance of discussing severe hypoglycemia and its associated signs and symptoms, these gaps narrow with discussion on the ease-of-use of Gvoke PFS and Gvoke Hypopen. The novel, ready-to-use glucagon delivery devices, such as Gvoke HypoPen and Gvoke PFS, provide opportunity for important and timely discussions that better educate, inform, and prepare patient and caregivers for the prompt delivery of glucagon during a severe hypoglycemia event.

\section{Keywords}

Hypoglycemia, Ease-of-use, Rescue, Liquid-stable glucagon, Pre-filled syringe, Auto- injector, Ready-to-use

\section{Introduction}

Hypoglycemia is a limiting factor in the glycemic management of diabetes [1,2] and causes recurrent morbidity in most patients with Type 1 Diabetes (T1D) and many with Type 2 Diabetes (T2D). Persons with T1D or T2D receiving insulin treatment are considered at risk of severe hypoglycemia. Current statistics estimate $\sim 6.8$ million Americans are on insulin therapy.

Citation: Meyer JM, Devona MC (2021) U.S. Survey Investigating Gaps between Patients and Specialists in the Treatment of Severe Hypoglycemia and Impressions of the Ease-of-Use of Liquid-Stable Glucagon for Subcutaneous Injection. Int Arch Endocrinol Clin Res 7:025. doi.org/10.23937/2572407X.1510025

Accepted: August 18, 2021: Published: August 20, 2021

Copyright: (C) 2021 Meyer JM, et al. This is an open-access article distributed under the terms of the Creative Commons Attribution License, which permits unrestricted use, distribution, and reproduction in any medium, provided the original author and source are credited. 
According to the ADA Standards of Care [3] glucagon should be prescribed for all individuals at increased risk of level 2 hypoglycemia, defined as blood glucose $<54 \mathrm{mg} / \mathrm{dL}(3.0 \mathrm{mmol} / \mathrm{L})$, or level 3 hypoglycemia, which denotes severe cognitive impairment requiring external assistance for recovery, so it is available should it be needed. However, nearly one-third of adults with T1D report that they do not have a current glucagon prescription [4].

While glucagon has demonstrated to be an effective treatment for severe hypoglycemia [5-7], the traditional Glucagon Emergency Kits (GEKs) require multiple steps of preparation to be able to mix, dose and properly administer. As a result of the complexity of preparation and administration of traditional glucagon kits, only $6-31 \%$ of caregivers can administer a full dose of glucagon in simulated emergency conditions [8-12]. Other usability studies have shown that $<13 \%$ of caregivers can successfully prepare and administer a full dose of glucagon during simulated emergencies, and from a patient perspective there is a desire for a glucagon format that provides prompt and reliable fulldose drug delivery [13].

Gvoke (glucagon injection) is a liquid formulation of glucagon that is stable at room temperature, and thus does not require reconstitution, and is available as an autoinjector (Gvoke HypoPen ${ }^{\circ}$ ) and pre-filled syringe (Gvoke ${ }^{\circ} \mathrm{PFS}$ ). Gvoke has demonstrated comparable clinical efficacy and achieved non-inferiority to GEKs [7], but instead utilizes a two-step process to administer the full-dose of glucagon. Usability studies demonstrated that $99 \%$ of both Gvoke HypoPen and Gvoke PFS users were able to successfully deliver a full-dose of glucagon in a simulated emergency setting $[8,12]$.

While usability studies have demonstrated high rates of successful delivery of a full-dose of glucagon, this study seeks to validate perceptions that Gvoke HypoPen and Gvoke PFS are easy-to-use and provide confidence in the ability to administer among patients, caregivers, and specialists.

Productive communication between Healthcare Practitioners (HCPs) and Persons with Diabetes (PWD) is essential when it comes to severe hypoglycemia, its signs and symptoms, and treatment options. Studies suggest, however, that there is a gap between how HCPs and PWDs communicate about hypoglycemia, which may have a detrimental effect on outcomes from Severe Hypoglycemic Events (SHEs). Patient perception of hypoglycemia often differs from clinical definitions [14]. There are also a variety of approaches to education including knowledge-based patient education (i.e., hypoglycemia symptoms, prevention, and treatment) as well as education on health beliefs, attitudes, and cognitive behavioral therapy [14]. This study seeks to identify the gaps that exist between PWD, caregivers, and specialists regarding severe hypoglycemia.

\section{Methods}

This is a quantitative survey study conducted online using the Voxco survey platform. The survey was distributed to all participants who opted in to participate through email along with electronic consent.

\section{Sample}

A total of 200 U.S.-based Health Care Providers (HCPs) and 400 U.S.-based diabetes patients and caregivers were consented to participate in an online survey using an email invitation between November $19^{\text {th }}$ and December 15, 2020. The HCP group was comprised of 100 adult endocrinologists and 100 pediatric endocrinologists who were verified from an NPI list and email addresses. The patient and caregiver groups comprised: 100 adults with Type 1 Diabetes (T1D), 100 adult caregivers of pediatric patients with Type 1 Diabetes (T1D CG), 100 adults with Type 2 Diabetes on Basal Insulin but not meal-time insulin (T2D BI), 100 adults with Type 2 Diabetes on basal and Mealtime Insulin (T2D MTI). The insulin regimen was self-reported by patients or caregivers.

The margin of error for this study was +/- 9.8 percentage points at the $95 \%$ confidence level for each of the sample groups of 100 respondents.

\section{Questionnaire}

The first part of the questionnaire consisted of questions developed to capture demographic information, including information about clinical practice and patient population for specialists (Table 1) and disease state information for patients and caregivers (Table 2). Survey questions were developed to identify gaps in training, knowledge, and the need for education when discussing severe hypoglycemia, as well as new products to treat severe hypoglycemia. Another set of questions were developed to explore the product characteristics and confidence in administration of Gvoke HypoPen and Gvoke PFS during a severe hypoglycemic event. The opinions and behaviors of the respondents were assessed using questions rated on a five-point Likert scale ranging from " 1 = strongly disagree" to " 5 = strongly agree".

\section{Data analysis}

All data was processed through SPSS version 27 (IBM Group, Armonk, NY) with statistical testing on comparison groups through Wincross 20 (Analytical Group, Scottsdale, AZ). All respondents completed the survey in full, therefore there were no incomplete surveys or the need for any imputation of data.

\section{Results}

The baseline characteristics for patients and caregivers are summarized in Table 1 and specialists are summarized in Table 2 . The majority $(>80 \%)$ of 
Table 1: Baseline demographics and clinical characteristics, patients and caregivers.

\begin{tabular}{|c|c|c|c|c|}
\hline & $\begin{array}{l}\text { T1D PWD } \\
\mathrm{N}=100\end{array}$ & $\begin{array}{l}\text { T1D CG } \\
N=100\end{array}$ & $\begin{array}{l}\text { T2D MTI } \\
\mathrm{N}=100\end{array}$ & $\begin{array}{l}\text { T2D BI } \\
N=100\end{array}$ \\
\hline \multicolumn{5}{|l|}{ Age, Caregivers, $\%^{1}$} \\
\hline $18-<40$ years & 19 & 20 & 9 & 12 \\
\hline$\geq 40-\leq 65$ years & 81 & 80 & 91 & 88 \\
\hline \multicolumn{5}{|l|}{ Age, Child² } \\
\hline $1-5$ years & - & 9 & - & - \\
\hline $6-11$ years & - & 42 & - & - \\
\hline $12-17$ years & - & 49 & - & - \\
\hline Female, $\%$ (Adults) $^{1}$ & 43 & 58 & 38 & 42 \\
\hline Prefer not to answer & - & 6 & - & 1 \\
\hline \multicolumn{5}{|l|}{ Relationship to Child with T1D, $\%^{1}$} \\
\hline Parent & - & 84 & - & - \\
\hline Aunt/Uncle & - & 10 & - & - \\
\hline Grandparent & - & 5 & - & - \\
\hline Other Family Member & - & 1 & - & - \\
\hline \multicolumn{5}{|l|}{ Type of Diabetes Therapy, $\%^{2}$} \\
\hline Oral therapy & 32 & 61 & - & 1 \\
\hline Basal insulin & 59 & 43 & 30 & 99 \\
\hline Meal-time insulin & 64 & 38 & 100 & 2 \\
\hline Other & 2 & 8 & 3 & 3 \\
\hline \multicolumn{5}{|l|}{$\begin{array}{l}\text { Concomitant Chronic Health Conditions \% } \\
\qquad(\text { excluding diabetes) })^{2}\end{array}$} \\
\hline Arthritis & 12 & 8 & 24 & 32 \\
\hline Alzheimer's disease & 3 & 4 & 3 & 2 \\
\hline Asthma & 17 & 13 & 21 & 18 \\
\hline Cardiovascular disease & 7 & 4 & 8 & 12 \\
\hline Depression & 21 & 17 & 36 & 36 \\
\hline Heart disease & 9 & 5 & 12 & 16 \\
\hline Osteoporosis & 3 & 3 & 3 & 5 \\
\hline Other & 4 & 1 & 7 & 3 \\
\hline $\begin{array}{c}\% \text { of Patients on insulin who experienced blood } \\
\text { sugar levels }<54 \mathrm{mg} / \mathrm{dL} \text { combined with one or more } \\
\text { symptoms of severe hypoglycemia in the last } 12 \\
\text { months }\end{array}$ & 95 & 96 & 90 & 86 \\
\hline \multicolumn{5}{|l|}{ Traditional Glucagon Kits Ever Purchased/Owned, \% } \\
\hline Glucagon Emergency Kit (Lilly) & 54 & 61 & 21 & 28 \\
\hline Glucagen HypoKit (Novo) & 34 & 52 & 24 & 30 \\
\hline Glucagon Emergency Kit (Fresenius) & 45 & 41 & 23 & 23 \\
\hline None & 13 & 6 & 49 & 40 \\
\hline
\end{tabular}

T1D PWD: Adult Type 1 patients; T1D CG: Caregivers of pediatric Type 1 patients; T2D MTI: Adult Type 2 patients on meal-time insulin; T2D BI: Adult Type 2 patients on basal insulin (but not meal-time insulin. ${ }^{1}$ Among caregivers. ${ }^{2}$ Among patients ${ }^{*}$ Reported by caregiver on behalf of child, ${ }^{* *}$ Self-reported

participants in each group were over the age of 40 . Greater than $90 \%$ of the patients on insulin claimed to have experienced blood sugar levels $<54 \mathrm{mg} /$ $\mathrm{dL}$ combined with one or more symptoms of severe hypoglycemia in the last 12 months, except for patients with T2D on basal insulin who reported at $86 \%$.

However, when queried about if they have ever owned a glucagon emergency preparation, affirmative responses ranged from $21-61 \%$, while $6-49 \%$ have never owned a glucagon emergency preparation. Additionally, adults with T2D on insulin were the patient types most likely to say they have never owned a glucagon emergency preparation (40-49\%). See Table 1 for additional information. 
Table 2: Baseline demographics and practice patterns, specialists.

\begin{tabular}{|c|c|c|}
\hline & $\begin{array}{l}\text { Endocrinologists } \\
\qquad N=100\end{array}$ & $\begin{array}{l}\text { Pediatric Endocrinologists } \\
\qquad N=100\end{array}$ \\
\hline Female, \% & 32 & 54 \\
\hline Prefer not to answer & - & 1 \\
\hline \multicolumn{3}{|c|}{ Years Practicing in current specialty, \% } \\
\hline $1-10$ years & 43 & 48 \\
\hline $11-20$ years & 37 & 27 \\
\hline $21-29$ years & 17 & 18 \\
\hline $30+$ years & 3 & 7 \\
\hline \multicolumn{3}{|c|}{$\%$ of time spent in direct patient care/clinical practice } \\
\hline $0-50 \%$ & - & - \\
\hline $51-75 \%$ & 1 & 14 \\
\hline $76-100 \%$ & 99 & 86 \\
\hline \multicolumn{3}{|c|}{ Region of Primary Practice Setting (\%) } \\
\hline Northeast & 29 & 32 \\
\hline South & 38 & 29 \\
\hline Midwest & 21 & 22 \\
\hline West & 12 & 17 \\
\hline \multicolumn{3}{|c|}{ Location of Primary Practice Setting (\%) } \\
\hline Rural & 2 & 1 \\
\hline Suburban & 70 & 38 \\
\hline Urban & 28 & 61 \\
\hline \multicolumn{3}{|c|}{$\begin{array}{c}\% \text { of patients with T1D or T2D within the past } 3 \\
\text { months who are insulin using }\end{array}$} \\
\hline $0-25 \%$ & 5 & - \\
\hline $26-50 \%$ & 56 & - \\
\hline $51-75 \%$ & 29 & 7 \\
\hline $76-100 \%$ & 10 & 93 \\
\hline \multicolumn{3}{|c|}{$\begin{array}{c}\% \text { of patients with T1D or T2D within the past } 3 \\
\text { months who are non-insulin using }\end{array}$} \\
\hline $0-25 \%$ & 8 & 95 \\
\hline $26-50 \%$ & 51 & 5 \\
\hline $51-75 \%$ & 34 & - \\
\hline $76-100 \%$ & 7 & - \\
\hline
\end{tabular}

Table 3: Survey results for patients with diabetes, caregivers, and specialists.

\begin{tabular}{|c|c|c|c|c|c|}
\hline & $\begin{array}{l}\text { T1D PWD } \\
N=100\end{array}$ & $\begin{array}{l}\text { T1D CG } \\
N=100\end{array}$ & $\begin{array}{l}\text { T2D MTI } \\
\mathrm{N}=100\end{array}$ & $\begin{array}{l}\text { T2D BI } \\
N=100\end{array}$ & $\begin{array}{c}\text { Specialists } \\
\qquad N=200\end{array}$ \\
\hline$\%$ who agree Gvoke HypoPen is easy-to-use & 95 & 94 & 94 & 93 & 95 \\
\hline $\begin{array}{c}\text { \% who agree Gvoke HypoPen gives confidence in } \\
\text { others' ability to administer treatment during severe } \\
\text { hypoglycemia episode }\end{array}$ & 94 & 98 & 88 & 92 & 94 \\
\hline $\begin{array}{c}\text { \% who agree Gvoke HypoPen gives confidence in } \\
\text { ability to self-administer treatment during severe } \\
\text { hypoglycemia episode }\end{array}$ & 86 & 91 & 93 & 93 & 90 \\
\hline$\%$ who agree Gvoke PFS is easy-to-use & 90 & 94 & 90 & 87 & 91 \\
\hline $\begin{array}{c}\text { \% who agree Gvoke PFS gives confidence in } \\
\text { others' ability to administer treatment during severe } \\
\text { hypoglycemia episode }\end{array}$ & 87 & 95 & 88 & 91 & 90 \\
\hline $\begin{array}{c}\text { \% who agree Gvoke PFS gives confidence in } \\
\text { ability to self-administer treatment during severe } \\
\text { hypoglycemia episode }\end{array}$ & 91 & 90 & 90 & 86 & 77 \\
\hline $\begin{array}{l}\% \text { who want HCP to proactively discuss } \\
\text { new treatment options for managing severe } \\
\text { hypoglycemia episodes }\end{array}$ & 89 & 98 & 85 & 84 & 72 \\
\hline
\end{tabular}


Nearly all participants (T1D $=95 \%$; T1D CG $=94 \%$; $\mathrm{T} 2 \mathrm{D} \mathrm{MTI}=94 \% ; \mathrm{T} 2 \mathrm{D} \mathrm{BI}=93 \% ;$ specialists $=95 \%$ ) believe that Gvoke HypoPen is easy-to-use. The strong majority of patients, caregivers of Type 1 Children, and specialists believe Gvoke products give confidence to self-administer treatment, and nearly all patients, caregivers of Type 1 children, and specialists believe Gvoke PFS and Gvoke HypoPen give confidence in other people's ability to administer treatment. See Table 3 for full results.

Patients with Type 2 Diabetes (T2D MTI $=49 \%$; T2D BI $=43 \%)$ and caregivers of children with Type 1 diabetes (47\%) both want to know more about Gvoke HypoPen as a treatment option. However, only half as many specialists compared to their patients are very likely to discuss this option. Specialists do proactively discuss new treatment options for severe hypoglycemia, but they want more information before they are ready to talk about this treatment option with their patients.

Regarding the importance of proactive discussions on the signs and symptoms of severe hypoglycemia endocrinologists of patients with T1D (88\%) and pediatric endocrinologists (96\%) report that this is an important topic to address with their patients; however, significantly fewer patients with T1D (54\%) and caregivers of patients with T1D (58\%) respond the same (Figure 1). While endocrinologists of patients with
T2D (88\%) report that signs and symptoms of severe low blood sugar are important to proactively discuss, only $59 \%$ and $62 \%$ of patients reported the same in the group of respondents with T2D on basal insulin and meal time insulin, respectively (Figure 1). A similar disconnect exists between endocrinologists, patients and caregivers regarding the importance of proactive discussions on situations where glucagon may be necessary to use. Endocrinologists of patients with T1D (89\%), endocrinologists of patients with T2D (84\%), and pediatric endocrinologists (90\%) placed much higher importance on glucagon use scenarios as compared to the patient groups (Figure 2).

Specialists tend to recommend glucagon use for the most severe signs and symptoms as opposed to a range of signs and symptoms or scenarios that are more patient-centric. Regardless of patient type, specialists focus their recommendations of glucagon to the most dangerous symptoms of severe hypoglycemia, including loss of consciousness (87-97\%) and seizure (79-97\%). In other scenarios where glucagon may be considered for use, there is a decrease in specialist recommendations to use glucagon. See Table 4 for the full results. In situations of feeling nervous about passing out and binge eating to correct the problem, notably fewer specialists recommend glucagon in these instances. In practice, specialists often discuss glucagon as treatment

\section{Situations where glucagon may be necessary to use $(\%)$}

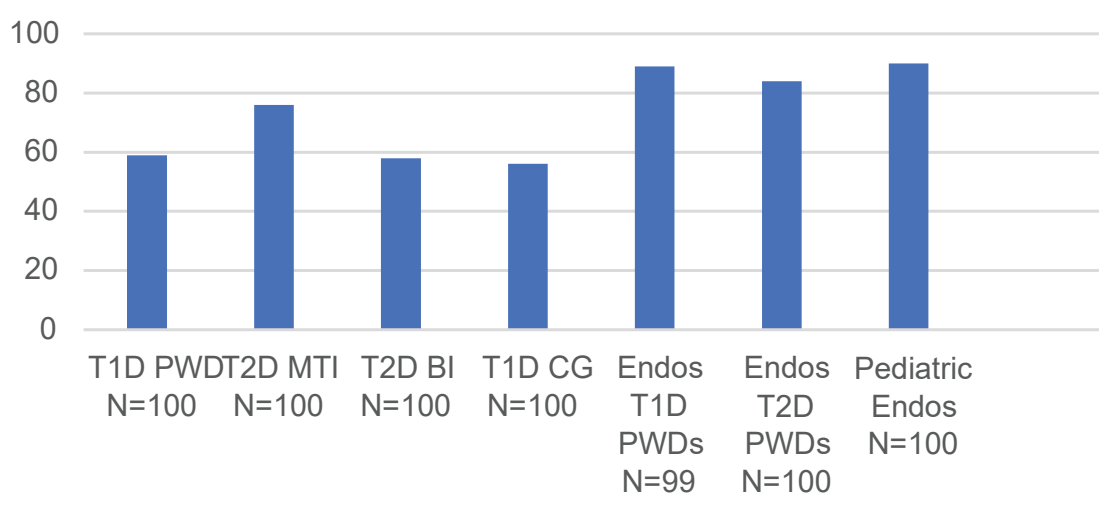

Figure 1: Importance of proactive discussions about severe low blood sugar signs and symptoms.

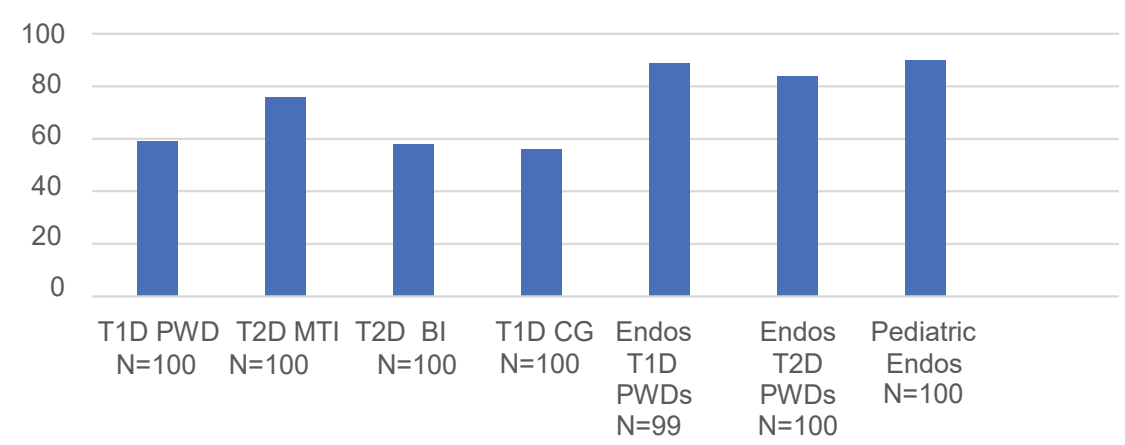

Figure 2: Importance of proactive discussions about situations where glucagon may be necessary to use 
for severe hypoglycemia as individual patients experience these symptoms -giving information to patients as needed, rather than before symptoms occur. The exception to this is for the most severe symptoms. Regardless of patient type, patients report having ever discussed glucagon as a treatment for individual severe hypoglycemia symptoms with their doctor at the same rate as having ever experienced symptoms. In the case of patients with T2D on meal-time and basal insulin and caretakers of children, doctors are taking a more proactive approach when discussing glucagon for treatment of severe symptoms. Of these patients, more have had discussions with their doctors about glucagon for treating severe symptoms than those who have ever experienced symptoms.

There are significant gaps between Type 1 patients, caregivers of children with T1D and specialists on when to administer glucagon for treatment of severe hypoglycemia (Table 4). Significantly fewer patients with T1D and caregivers of Children with T1D would administer glucagon for specific symptoms (i.e. having a seizure, being combative/uncooperative), compared to when doctors say they should administer glucagon for these symptoms. While there are gaps between patients with T1D and specialists, similar numbers of patients with T1D who experienced certain symptoms would administer Gvoke HypoPen for those same symptoms, such as when feeling nervous about possibly passing out or instead of binge eating to correct low blood sugar (Table 4). This indicates that patients with T1D simply need more education from their specialists on when to administer treatment. Caregivers of children with T1D are likely skeptical of administering glucagon and/or specific brands of glucagon to their child without more information from their own research or their doctor. Patients with T2D on meal-time and basal insulin tend to have narrower gaps when it comes to when they would use Gvoke HypoPen for symptom treatment and when specialists think they should use glucagon. For more severe symptoms, specialists are more likely to say patients should take glucagon. In the case of binge eating as a symptom, patients with $T 2 D$ are more likely to say they would take Gvoke HypoPen as treatment than specialists who say they should take glucagon. When repeatedly trying to correct the problem with food and seeing no increase in blood sugar for an extended period, equally as many specialists and patients say they should or would use glucagon.

In many cases, just as many patients and specialists say they would or should self-administer glucagon for treatment of severe hypoglycemia. There is a gap in explaining the nuance of appropriate use of glucagon for eating-related symptoms, as specialists recommend glucagon administration for repeat eating symptoms but not for binge eating. Specialists of adult and pediatric patients are more likely to say that patients

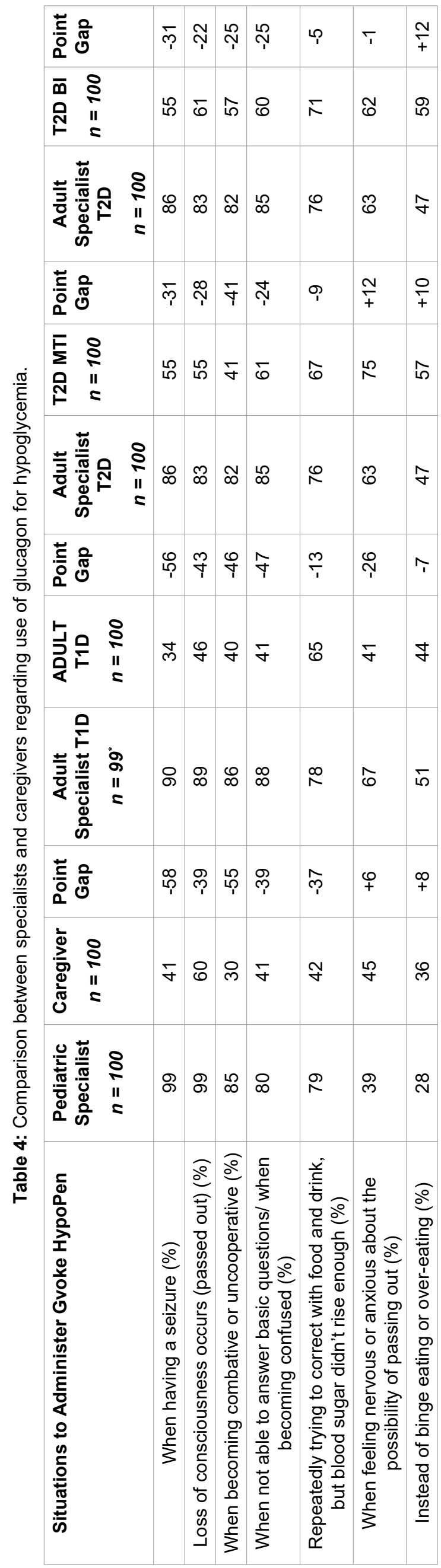


should administer glucagon in situations of repeat eating to correct severe hypoglycemia rather than when binge eating. Since patients will typically repeatedly eat and then move to binge eating to correct severe hypoglycemia, specialists recommend use of glucagon more for the first symptom to avoid the second one. There is an opportunity to convey to specialists the importance of recommending glucagon in both scenarios in the event patients do not administer glucagon for repeat eating or who only binge eat to correct the problem.

\section{Discussion}

While a number of studies have demonstrated the usability of Gvoke HypoPen and Gvoke PFS in a simulated emergency setting [8-12], the perception of ease-of-use after being shown both the instructions for use and the devices themselves is also important; especially considering the limited time physicians, patients, and caregivers have for education during routine office visits. Questioning the ease-of-use of these ready-to-use formulations of glucagon naturally leads to questions on whether the various groups queried have confidence in the ability of others to administer the product. Given the low usability of traditional glucagon kits [8-10], it is extremely important to demonstrate that novel product offerings instill more confidence in the endusers. Related to this concept is the idea of confidence in the self-administration of ready- to-use formulations of glucagon. Severe hypoglycemia is typically defined as an event requiring the assistance of another person to actively administer fast acting carbohydrates, glucagon, or perform other resuscitative actions [2]. However, the use of glucagon is recommended when an individual: has tried unsuccessfully to correct with carbohydrates, is unable or unwilling to take carbohydrates by mouth, or is unresponsive and needs assistance (eg, seizure or unconscious) [3]. In other real-life scenarios, there may be situations when an individual is alone and does not have access to fast-acting carbohydrates. Due to these various scenarios, it is important to also assess each group's confidence in the ability to self-administer ready-to-use glucagon formulations.

Patients and caregivers are interested in learning about ready-to-use glucagon options, like Gvoke HypoPen and Gvoke PFS, but responses from specialists show that this topic is not a priority during their consults with patients on insulin to have proactive conversations about the value of having glucagon onhand. About a third of patients across the queried groups were very interested in learning more about Gvoke PFS. In particular, patients with T2D on basal insulin and caregivers of children with T1D had the strongest interest. However, significantly fewer specialists of these patients say they are very likely to discuss this product with them. The reasons for this may be multi-factorial considering the enormity of clinical care instruction surrounding glycemic control, medication management, and the prevention of microand macrovascular complications paired with the everdecreasing time able to be spent with patients.

One of the most important aspects of education on hypoglycemia is the recommendation that patients with diabetes have access to a source of glucose for mild to moderate episodes, and a glucagon formulation for cases of severe hypoglycemia [15]. The American Diabetes Association (ADA) recommends that glucagon be prescribed for all individuals at increased risk of level 2 and Level 3 hypoglycemia [3]. The recommendation to have life-saving tools available and accessible is not enough, as these tools will often need to be administered not only by the patient, but also by friends, family members, and caregivers. Thus, hypoglycemia education and awareness must extend to these extended care team members, which includes being able to prepare and administer glucagon preparations in a non-hospital setting.

It has been well-documented that friends and family members felt uncertainty and voiced concerns over being able to properly administer traditional glucagon kits in an emergency situation [16]. Human factor and usability studies identified preparation and administration inaccuracies and handling difficulties even after verbal education on these kits.

This study finds that while patients, caregivers, and specialists agree that severe hypoglycemia is an important topic to learn and discuss, significant gaps in perceptions exist between the groups and barriers to action in education and treatment of severe hypoglycemia could inhibit appropriate care. In this study, patients responded that they want their doctors to proactively discuss new treatments options for severe hypoglycemia episodes, while just as many of their specialists say they already do so. So, there is some breakdown in perception of the amount of time or frequency with which these treatments are discussed versus what is happening in reality.

Most patients with Type 2 diabetes report it is extremely important to proactively discuss the signs and symptoms of severe hypoglycemia, but significantly fewer specialists of patients with T2D respond with the same urgency. In contrast, specialists think it's extremely important to discuss these signs and symptoms with their patients with T1D, while less than half of patients with T1D feel the same. Studies have shown that $30-40 \%$ of patients with Type 1 diabetes experience 1-3 severe hypoglycemic events per year $[1,17,18]$. While less frequent and more difficult to quantify due to the heterogeneity of the population, some studies have noted that $20 \%$ of patients with Type 2 diabetes experience at least 1 severe hypoglycemic event per year $[19,20]$. While the perception of the importance of education on severe hypoglycemia varies 
between groups, reports indicate that individuals are still at risk, regardless of glycemic control. Predictive models have identified the strongest predictors of longterm risk of severe hypoglycemia are intensive glycemic management and insulin use [21].

While specialists are most likely to recommend using glucagon as a treatment for severe hypoglycemia for the most severe symptoms, including loss of consciousness and seizures, they are not being consistently proactive in talking about glucagon as a treatment option for severe hypoglycemia with all of their patients on insulin. Just as many caregivers of patients with type 1 diabetes whose child experienced a symptom of severe hypoglycemia say their specialist discussed the glucagon as a treatment option for those symptoms. For severe symptoms, like unconsciousness, caregivers report their specialist take an even more proactive approach and discussed glucagon with them without their child having symptoms.

Specialists address the symptoms and treatment of patients with Type 1 diabetes, but they are not doing so proactively. For patients with Type 1 diabetes who experienced symptoms of severe hypoglycemia, a similar number say their Specialist discussed glucagon as a treatment option for those symptoms. This suggests those who have not yet had symptoms may be unaware of potential care options. In contrast, specialists are taking steps to inform their patients with Type 2 diabetes on meal-time insulin of glucagon as a treatment option for the most severe symptoms of severe hypoglycemia, regardless of whether Patients have had symptoms or not. For most other symptoms, similar numbers of patients with Type 2 diabetes on meal-time insulin say they have experienced symptoms and talked about glucagon for treatment.

Specialists are taking steps to inform their patients with Type 2 diabetes on meal-time insulin of glucagon as a treatment option for the most severe symptoms of severe hypoglycemia regardless of whether patients have had symptoms or not. For most other symptoms, similar numbers of patients with Type 2 diabetes on meal-time insulin say they have experienced symptoms and talked about glucagon for treatment. For most scenarios, patients with Type 2 diabetes on basal insulin discussed glucagon as a treatment option for severe hypoglycemia with their specialist, whether they have ever experienced symptoms. Specialists of these patients have been proactive in their approach to informing their patients of important treatment information.

The identification of gaps in knowledge, understanding, and the perception of severe hypoglycemia and its treatments are important to help shape the education and training of patients with diabetes at physician visits. While many recognize severe hypoglycemia to be an important, life-threatening condition, less than $10 \%$ of patients with diabetes on insulin currently have a filled prescription of glucagon (IQVIA, DataMonitor, CDC Survey). This highlights the potential for therapeutic inertia and reluctance to proactively discuss and prescribe glucagon to patients on insulin, which may have been more of an issue before easier delivery forms of glucagon were available.

The strong patient voice in this survey speaks to patients' need for proactive information and education, and opportunity for healthcare providers to shape the discussion, process in care, and considerations for future. In future research efforts, it is important to identify these gaps and provide healthcare professionals, patients, and caregivers with the same lexicon to continue these discussions.

\section{Acknowledgements}

This research was supervised by Wakefield Research with Paul Bragan the principal investigator.

\section{Disclosure Statement}

Authors are employees of Xeris Pharmaceuticals, Inc., Chicago, IL.

\section{Funding Sources}

This work was supported by Xeris Pharmaceuticals, Inc., Chicago, IL.

\section{References}

1. Cryer PE (2008) The barrier of hypoglycemia in diabetes. Diabetes 57: 3169-3176.

2. Cryer PE (2012) Severe hypoglycemia predicts mortality in diabetes. Diabetes Care 35: 1814-1816.

3. American Diabetes Association (2020) Glycemic targets: Standards of Medical Care in Diabetes-2020. Diabetes Care 43: S66-S76.

4. Haymond MW, Liu J, Bispham J, Hickey A, McAuliffeFogarty AH (2019) Use of Glucagon in Patients with Type 1 Diabetes. Clin Diabetes 37:162-166.

5. Glucagon Emergency Kit (2018) Indianapolis, In: Eli Lilly and Company.

6. GlucaGen $®$ (glucagon) for injection Hypokit $\circledast$ Prescribing Information. Novo Nordisk Inc, USA.

7. Gvoke (2019) Chicago, IL: Xeris Pharmaceuticals, Inc.

8. Newswanger B, Ammons S, Phadnis N, Ward WK, Castle J, et al. (2015) Development of a Highly Stable, Nonaqueous Glucagon Formulation for Delivery via Infusion Pump Systems. J Diabetes Sci Technol 9: 24-33.

9. Ching K, Andre A, Crick M, et al. (2015) Biodel's glucagon emergency management auto reconstitution device demonstrates superior usability compared to marketed glucagon kits in human factors study. Abstract presented at Diabetes Technology Meeting 22-24.

10. Valentine V, Newswanger B, Prestrelski S, Andre AD, Garibaldi M, et al. (2019) Human Factors Usability and Validation Studies of a Glucagon Autoinjector in a Simulated Severe Hypoglycemia Rescue Situation. Diabetes Technol Ther 21: 522-530. 
11. Rylander D Jr (2015) Treating severe hypoglycemia: rapid mixing of lyophilized glucagon and diluent at point of care with the Enject GlucaPen. J Diabetes Sci Technol 9: 34-37.

12. Settles JA, Gerety GF, Spaepen E, Suico JG, Child CJ (2020) Nasal glucagon delivery is more successful than injectable delivery: a simulated severe hypoglycemia rescue. Endocr Pract 26: 407-415.

13. Yale JF, Dulude $H$, Egeth $M$, Piche CA, Lafontaine $M$, et al. (2017) Faster use and fewer failures with needlefree nasal glucagon versus injectable glucagon in severe hypoglycemia rescue: a simulation study. Diabetes Technol Ther 19: 423-432.

14. Kalra S, Mukherjee JJ, Venkataraman S, Bantwal G, Shaikh S, et al. (2013) Hypoglycemia: the neglected complication. Indian J Endocrinol Metab 17: 819-834.

15. Kedia N (2011) Treatment of severe diabetic hypoglycemia with glucagon: an underutilized therapeutic approach. Diabetes Metab Syndr Obes 4: 337-346.

16. Harris G, Diment A, Sulway M, Wilkinson M (2001) Glucagon administration-underevaluated and undertaught. Pract Diabetes Int 18: 22-25.
17. Davis HA, Spanakis EK, Cryer PE, Davis SN (2000) Hypoglycemia During Therapy of Diabetes. In: Feingold $K R$, Anawalt B, Boyce A, et al. Endotext.

18. International Hypoglycaemia Study Group (2015) Minimizing hypoglycemia in diabetes. Diabetes Care 38: 1583- 1591.

19. Gehlaut RR, Dogbey GY, Schwartz FL, Marling CR, Shubrook JH (2015) Hypoglycemia in Type 2 Diabetes-More Common Than You Think: A Continuous Glucose Monitoring Study. J Diabetes Sci Technol 9: 999-1005.

20. Edridge CL, Dunkley AJ, Bodicoat DH, Rose TC, Gray LJ, et al. (2015) Prevalence and Incidence of Hypoglycaemia in 532,542 People with Type 2 Diabetes on Oral Therapies and Insulin: A Systematic Review and Meta-Analysis of Population Based Studies. PLoS One 10: e0126427.

21. Chow LS, Zmora R, Ma S, Seaquist ER, Schreiner PJ (2018) Development of a model to predict 5- year risk of severe hypoglycemia in patients with type 2 diabetes. BMJ Open Diabetes Res Care 6: e000527. 